\title{
Analytical Validation of Ameziniummetilsulfate by HPLC in Human Blood Plasma from Uremia Patient Treated by Dialysis
}

\section{H Shintani ${ }^{1 *}$ and F Hayashi}

${ }^{1}$ School of Science, Chuo University, 1-13-27, Kasuga, Bunkyo, Tokyo 112-0003, Japan

${ }^{2}$ Health care facility of Namiki hospital. 2-10-22, Uchidabashi, Minamiku, Nagoya, Japan

\begin{abstract}
Summary
A high-performance liquid chromatography (HPLC) method using an internal standard is validated for the determination of 4-amino-6-methoxy-1-phenyl-pyridozinium methyl sulfate (ameziniummetilsulfate, AM) in a uremia patient treated by artificial dialysis. The method involves liquid-liquid extraction and ion-suppressed reverse-phase HPLC on an end-capped C-18 column. There is no interference by plasma components or AM metabolites in the HPLC analysis. Average recovery rate using liquid -liquid extraction was $88.7 \%$ and limit of determination (LOD) was $2 \mathrm{ng} / \mathrm{ml}$. This concentration was sufficient to determine AM in human plasma. Accuracy and precision was $<5.6 \%$ and $16.2 \%$, respectively, at $2 \mathrm{ng} / \mathrm{ml}$, LOD.
\end{abstract}

Keywords: Column liquid chromatography; Ameziniummetilsulfate; Uremia; Dialysis

\section{Introduction}

Ameziniummetilsulfatc (AM) is an antihypotensive agent. During artificial dialysis, the blood pressure of uremia patients was found to decrease. To prevent this decrease during artificial dialysis, one tablet of AM (10mg tablet) was orally administered to maintain blood pressure $[1,2]$. It has been reported that combined administration of $\mathrm{AM}$ and grapefruit juice is effective in maintaining blood pressure due to inhibition of AM metabolism by some compounds contained in grapefruit juice. It was speculated that polyphenol, antioxidant, containing in grapefruit may participate in the favorable reaction. Dialysis is carried out in the conventional way. Artificial dialysis was conducted three times per week and $4 \mathrm{~h}$ for each treatment.

Several aspects of AM have already been discussed [3-18]. In these papers it has proved its value in the treatment of postural cardiovascular dysregulations in humans with a regimen of $10 \mathrm{mg}$ b. i. d. (bis in die, twice a day). The pharmacokinetic behavior of AM has been described [8-9]; it differs depending on the patient's metabolic rate, sensitivity and so on. The study of the pharmacokinetics of blood concentration of AM is not always the best way to evaluate the efficiency of blood AM. This is because blood pressure data and blood AM concentration do not always coincide satisfactorily. Therefore, determination of AM in blood was regarded as one candidate as an indicator for evaluation of the effectiveness of blood AM. It is the result of our experiment of comparing blood pressure data with that of blood concentration of AM [1] that the pharmacokinetic study of blood AM is not always the best procedure for evaluation of AM effectiveness.

Since AM has been introduced into therapy, the validation study of the accurate, precise and reproducible determination of AM concentrations in human blood is required. Thus, a selective and sensitive method is urgently required for precise analysis of blood AM. A method of determination can be found in the literature [18]. However, the method reported is neither specific nor selective [18]. The HPLC determination is more selective and sensitive [19] and is more appropriate for our purpose. AM analysis by HPLC has been reported, but the chromatographic baseline fluctuated [19]. The AM peak exhibited "fronting" [19] that may be due to the use of non-endcapped silica based instead of the endcapped C-18 column used in this experiment. It is likely that basic compounds exhibit tailing on residual silica surfaces especially when used non-endcapped columns. This is typical when used a silica-based column. Polymer-based columns such as polystyrene do not show such significant tailing even if an amino compound is analyzed [20-22]. Additionally, it is inappropriate that cation-exchange columns used for pretreatment of AM in blood should be capacity dependent [19], the method is inappropriate since it is not easily to predict when column capacity is saturated [19]; this is another handicap. The chromatographic propriety in Reference [19] cannot be sufficiently evaluated; therefore a more precise and reliable pretreatment method is required which is the aim of this study.

This paper describes the analytical validation study of the development and evaluation of a selective determination of AM in the lower nanogram range. It employs a liquid-liquid extraction pretreatment and subsequent separation. Quantitative analysis is by ion-suppression, reverse-phase HPLC combined with an endcapped C-18 column. Using these methods, the time course (change of amount with time) of AM in the blood of uremia patients treated by artificial dialysis was conducted for pharmacokinetic studies of blood AM.

\section{Experimental}

\section{Materials}

Ameziniummetilsalfate (AM): AM tablets were from Dainippon Pharmaceutical Co. Ltd. (Tokyo, Japan). One tablet normally contains $10 \mathrm{mg}$ AM. The trade name is Lizmic ${ }^{\mathrm{R}}$. The AM analytical reagent was from Ohara Pharmaceutical Co. Ltd. (Tokyo, Japan). Purity of the

*Corresponding author: Hideharu Shintani, 1-10-60, Minamidaira, Hino, Tokyo, 191-0041 Japan, Tel: 042-592-2336; E-mail: shintani@mail.hinocatv.ne.jp

Received September 11, 2011; Accepted December 10, 2011; Published December 12, 2011

Citation: Shintani H, Hayashi F (2011)Analytical Validation of Ameziniummetilsulfate by HPLC in Human Blood Plasma from Uremia Patient Treated by Dialysis. Pharm Anal Acta S11:004. doi:10.4172/2153-2435.S11-004

Copyright: (C) 2011 Shintani H, et al. This is an open-access article distributed under the terms of the Creative Commons Attribution License, which permits unrestricted use, distribution, and reproduction in any medium, provided the original author and source are credited. 
Citation: Shintani H, Hayashi F (2011) Analytical Validation of Ameziniummetilsulfate by HPLC in Human Blood Plasma from Uremia Patient Treated by Dialysis. Pharm Anal Acta S11:004. doi:10.4172/2153-2435.S11-004

Page 2 of 6

reagent was, chromatographically, $100 \%$. The chemical structure of $\mathrm{AM}$ is in (Figure 1).

Internal standard (IS) 2-phenylimidazole (Aldrich Co.) was used for HPLC analysis. The structure of 2-phenylimidazole is also in Figure I (the upper is AM and the lower is IS).

All other reagents used were of the best commercially available quality.

AM Administration procedure: AM was orally administered immediately prior to artificial dialysis treatment. Human blood was sampled from three different uremia patients (patients A, B and C) treated by artificial dialysis at Namiki hospital in Nagoya, Japan. Blood plasma was prepared in the conventional way using heparin addition combined with centrifugation at Namiki hospital.

Patient $\mathrm{A}$ is a 57 year old male with 42 month dialysis history, patient $\mathrm{B}$ is a 68 year old female with 22 month dialysis history and patient $\mathrm{C}$ is a 60 year old female with 68 month dialysis history. Their disease is uremia.

Preparation of original standard solution of AM: $10 \mathrm{mg}$ AM was precisely dissolved with $10 \mathrm{ml}$ methanol to obtain a $1000 \mu \mathrm{g} / \mathrm{mL}$ solution.

Preparation of diluted standard solution of AM: From the original standard solution prepared above, the following diluted standard solutions were prepared, using as diluent an aqueous solution containing $0.01 \%$ trimethylamine and $0.005 \%$ phosphoric acid $(\mathrm{D} / \mathrm{L})$ (Table 1). The standard solutions D to I in (Table 1) were used for preparation of a standard curve.

Preparation of original standard solution of IS of 2-phenylimidazole: $10.0 \mathrm{mg}$ 2-phenylimidazole dissolved in methanol was diluted to $10 \mathrm{~mL}$ precisely $(1000 \mu \mathrm{g} / \mathrm{mL})$.

Preparation of dilute standard solution of IS of 2-phenylimidazole: From original standard solution prepared above, the following diluted IS solution was prepared.

$1.0 \mathrm{~mL}$ original solution of IS $(1000 \mu \mathrm{g} / \mathrm{mL})$ diluted to $10 \mathrm{~mL}$ with water. (IS concentration $100 \mu \mathrm{g} / \mathrm{mL}$ ) -J $0.1 \mathrm{~mL}$ J diluted to $10 \mathrm{~mL}$
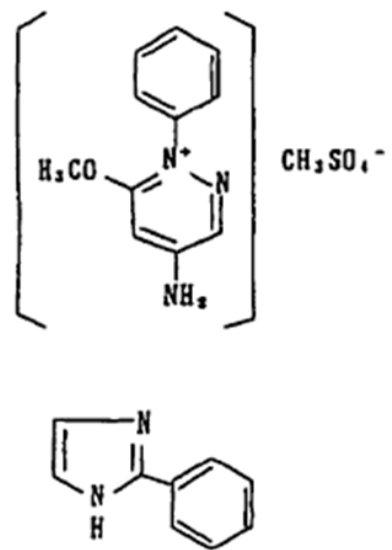

Figure 1: Chemical structures of AM and 2-phenylimidazole used as IS. Upper AM, lower IS.
$1.0 \mathrm{~mL}$ original $\mathrm{AM}$ standard solution $(1000 \mu \mathrm{g} / \mathrm{mL})$ diluted to $10 \mathrm{~mL}$ with $\mathrm{D} / \mathrm{L}$.

$[\mathrm{AM}]=$

$100 \mu \mathrm{g} / \mathrm{mL}-\mathrm{A}$

$2.0 \mathrm{~mL}$ A diluted to $20 \mathrm{~mL}$ with $\mathrm{D} / \mathrm{L}$. [AM] $=10 \mu \mathrm{g} / \mathrm{mL}-\mathrm{B}$

$4.0 \mathrm{~mL} B$ diluted to $10 \mathrm{~mL}$ with $\mathrm{D} / \mathrm{L}$. [AM] $=4 \mu \mathrm{g} / \mathrm{mL}-\mathrm{C}$

$4.0 \mathrm{~mL} B$ diluted to $25 \mathrm{~mL}$ with $\mathrm{D} / \mathrm{L}$. [AM] $=1.6 \mu \mathrm{g} / \mathrm{mL}-\mathrm{D}$

$0.8 \mathrm{~mL} B$ diluted to $10 \mathrm{~mL}$ with $\mathrm{D} / \mathrm{L}$. [AM] $=0.8 \mu \mathrm{g} / \mathrm{mL}-\mathrm{E}$

$1.0 \mathrm{~mL} \mathrm{C}$ diluted to $10 \mathrm{~mL}$ with $\mathrm{D} / \mathrm{L}$. [AM] $=0.4 \mu \mathrm{g} / \mathrm{mL}-\mathrm{F}$

$2.5 \mathrm{~mL}$ D diluted to $20 \mathrm{~mL}$ with $\mathrm{D} / \mathrm{L}$. [AM] $=0.2 \mu \mathrm{g} / \mathrm{mL}-\mathrm{G}$

$2.5 \mathrm{~mL} E$ diluted to $20 \mathrm{~mL}$ with $\mathrm{D} / \mathrm{L}$. [AM] $=0.1 \mu \mathrm{g} / \mathrm{mL}-\mathrm{H}$

$1.0 \mathrm{~mL} F$ diluted to $10 \mathrm{~mL}$ with $\mathrm{D} / \mathrm{L}$. [AM] $=0.04 \mu \mathrm{g} / \mathrm{mL}-$ -

Table 1: The original standard solution.

with water. (IS concentration $1 \mu \mathrm{g} / \mathrm{mL}$ ) -K Solution $\mathrm{K}$ was used for IS solution.

Preparation of human plasma stability test solution: $1.0 \mathrm{~mL}$ AM standard solution of I ( $40 \mathrm{ng} / \mathrm{mL})$ was spiked into $19 \mathrm{~mL}$ human plasma $(2 \mathrm{ng} / \mathrm{mL})$ and $1 \mathrm{~mL}$ AM standard solution of $\mathrm{E}(800 \mathrm{ng} / \mathrm{mL})$ was spiked into $19 \mathrm{~mL}$ human plasma $(40 \mathrm{ng} / \mathrm{mL})$. These were used for stability validation tests during storage.

Preparation of standard curve: $50.0 \mu \mathrm{L}$ AM standard solution at concentrations of $0.04,0.1,0.2,0.4,0.8$ and $1.6 \mu \mathrm{g} / \mathrm{mL}$ (D to I) were spiked with $50 \mu \mathrm{L}$ IS $(1 \mu \mathrm{g} / \mathrm{mL})$. They were evaporated by blowing with nitrogen gas for $20 \mathrm{~min}$ at $50^{\circ} \mathrm{C}$ and the residue dissolved in 200 $\mu \mathrm{L}$ HPLC mobile phase $\left(0.1 \mathrm{M} \mathrm{KH}_{2} \mathrm{PO}_{4}: \mathrm{CH}_{3} \mathrm{CN}=2: 3\right)$ and stirred thoroughly. $100.0 \mu \mathrm{L}$ were applied to the HPLC chromatograph.

Preparation of human plasma-spiked AM standard solution: $1.0 \mathrm{~mL}$ human plasma was spiked with $50 \mu \mathrm{L}$ AM standard solution at concentrations of $0.04,0.8$ and $1.6 \mu \mathrm{g} / \mathrm{mL}$. These were additionally spiked with $50 \mu \mathrm{L}$ IS $(1 \mu \mathrm{g} / \mathrm{mL})$ and additional recovery tests conducted following the analytical procedure described below.

\section{Analytical procedure}

Uremia patients were administered AM and thereafter treated by artificial dialysis. $1.0 \mathrm{~mL}$ samples of their plasma were extracted with $10 \mathrm{~mL}$ of a solvent mixture of dichloromethane and 2-propanol (9: 1 $\mathrm{v} / \mathrm{v}) .50 .0 \mu \mathrm{L}$ ammonia solution ( $28 \%$, concentrated ammonia solution) were added for ion-suppression of basic compounds of AM and IS.

These samples were shaken for $5 \mathrm{~min}$, centrifuged at $1000 \mathrm{~g}$ for $10 \mathrm{~min}$ at $20{ }^{\circ} \mathrm{C}$ and the supernatent liquid discarded. $8.0 \mathrm{~mL}$ of the residual organic layer were retrieved and evaporated with a nitrogen stream for $20 \mathrm{~min}$ at $50^{\circ} \mathrm{C}$. The residue was re-dissolved with $200 \mu \mathrm{L}$ HPLC mobile phase $\left(0.1 \mathrm{M} \mathrm{KH}_{2} \mathrm{P}_{4}: \mathrm{CH}_{3} \mathrm{CN}=2: 3\right)$ and stirred well; $100.0 \mu \mathrm{L}$ were injected into the HPLC chromatograph.

\section{HPLC Condition}

Equipment used comprised a Rheodyne sample injector with 100 $\mu \mathrm{L}$ loop, Type 7125, high-pressure pump unit, Waters Type 6000A, HPLC column and Capcell Pack ${ }^{\mathrm{R}}$ SCX UG 80 (silicone coated C-18 column) from Shiseido Co.(Tokyo, Japan), 250 x 4.6mm. Column temperature was $45{ }^{\circ} \mathrm{C}$; UV detector, Jasco-Uvidec-100 $\mathrm{III}^{\mathrm{R}}$ (Tokyo, Jaapn), operated at $289 \mathrm{~nm}$. The mobile phase was a mixture of 0.1 $\mathrm{M}$ potassium hydrogen phosphate-acetonitrile $(2: 3, \mathrm{v} / \mathrm{v})$. Flow rate was $1.0 \mathrm{~mL} / \mathrm{min}$ and injection volume was $100 \mu \mathrm{L}$.

\section{Calculation of AM in blood plasma}

AM in blood plasma was calculated from a prepared standard curve. 


\section{Validation study of analytical conditions}

Approved specificity: Specificity can be confirmed whether AM in plasma is free from admixtures of blood components and IS spiked. If AM is free from any components in blood plasma and IS, liquid-liquid extraction combined with HPLC can be considered as satisfactory procedure.

Approved linearity of standard curve: If the range of coefficient of correlation is more than 0.99 , the range is regarded as linear in analytical validation study. For the preparation of a standard curve, 0 , 2, 5, 10, 20, 40 and $80 \mathrm{ng} / \mathrm{mL}$ concentrations of AM in human blood plasma were used.

Approved limit of determination (LOD): A concentration $>$ the limit of detection $(\mathrm{S} / \mathrm{N}=2)$, within $20 \%$ of the reliability of determination accuracy and within $20 \%$ of precision can be regarded as a satisfactory LOD. For the determination of LOD in this experiment, 2 $\mathrm{ng} / \mathrm{mL} \mathrm{AM}$ in plasma was used.

\section{Reproducibility}

Repeated reproducibility: Repeated reproducibility was studied over the linearity range of the standard curve with $>0.99$ of coefficient of correlation. The AM concentrations used were $2 \mathrm{ng} / \mathrm{mL}$ close to the LOD, $40 \mathrm{ng} / \mathrm{mL}$ as the middle range and $80 \mathrm{ng} / \mathrm{mL}$ as the highest range. Accuracy and precision of repeated injection reproducibility were validated.

Intra-Laboratory reproducibility: Time-to-time, day-to-day and month-to-month variations within the same laboratory were studied. Accuracy and precision were validated from the average value of each experiment.

\section{Storage stability test}

Stability test of spiked AM, human Blood Plasma Stored at $-80^{\circ} \mathrm{C}$. Stability of human blood plasma spiked at $2 \mathrm{ng} / \mathrm{mL}$ or $40 \mathrm{ng} / \mathrm{mL} \mathrm{AM}$ was tested after 1 and 2 weeks storage. Number of samples for each test was three $(\mathrm{n}=3)$.

Stability test of standard solution of AM: A stability test of standard $\mathrm{AM}$ solution was conducted at $4^{\circ} \mathrm{C}$ for 2 weeks, after which standard solutions of AM were freshly prepared as controls. From comparison of both peaks, storage stability was validated.

Stability of AM in auto sampler at $4^{\circ} \mathrm{C}: 1.0 \mathrm{~mL}$ human blood plasma spiked at $2 \mathrm{ng} / \mathrm{mL}$ or $40 \mathrm{ng} / \mathrm{mL}$ AM was prepared and stored for 3 days at $4^{\circ} \mathrm{C}$. Stability was validated from peak height comparison of initial day value and that of three days after.

Stability of evaporation conditions of AM: For AM extraction in plasma, evaporation in a nitrogen stream was at $55^{\circ} \mathrm{C}$, so the flow period was validated from the results of peak heights after 15, 30 and 60 min flow. Human blood plasma spiked with $2 \mathrm{ng} / \mathrm{mL}$ or $40 \mathrm{ng} / \mathrm{mL}$ AM was used. Number of samples tested for each was three $(n=3)$.

\section{Result and Discussion}

\section{Specificity}

(Figure 2) shows the HPLC chromatogram blank for human plasma and that of human plasma spiked at $80 \mathrm{ng} / \mathrm{mL}$ AM. No interference peak could be observed in any samples tested.

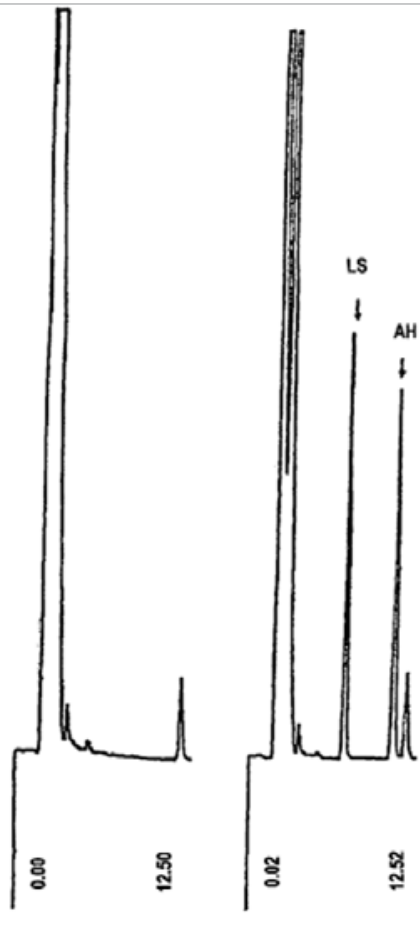

Figure 2: HPLC chromatogram of blood plasma with or without AM administration to uremia patient treated by artificial dialysis. Left: Blank of human plasma, Right: Human plasma spiked with $80 \mathrm{ng} / \mathrm{mL}$ AM. IS internal standard of 2-phenylimidazole. AM ameziniummetilsalfate.

\section{Linearity}

From $>0.99$ of coefficient of correlation, the linearity range of the standard curve was $0-80 \mathrm{ng} / \mathrm{mL}$.

\section{Reproducibility}

In (Table 2), recovery rates are shown. Average recovery rate was $88.7 \%$. Reproducibility was corrected for recovery rate. Both accuracy and precision of LOD at $2 \mathrm{ng} / \mathrm{mL}$ were $<20 \%$. Those $>2 \mathrm{ng} / \mathrm{mL}$ were within $15 \%$.

Reproducibility of intra-laboratory results was within $15 \%$ at concentrations tested (Table 3). From the results, the LOD was defined as $2 \mathrm{ng} / \mathrm{mL}$.

\section{Stability}

The stability results for storage at $-80^{\circ} \mathrm{C}$ are in (Table 4). That of the standard solution is in (Table 5). That of analytical samples stored in the autosampler is in (Table 6). That of evaporation conditions is in (Table 7).

AM was stabilized for 2 weeks at $-80^{\circ} \mathrm{C}$, AM standard solution was stabilized for 2 weeks at $4^{\circ} \mathrm{C}$, AM analytical sample was stabilized for 3 days in the autosampler at $4^{\circ} \mathrm{C}$ and evaporation conditions for $\mathrm{AM}$ were stabilized for up to $60 \mathrm{~min}$.

\section{AM Time course of human plasma from uremia patients treated by dialysis}

AM was orally administered to three uremia patients immediately prior to artificial dialysis to maintain blood pressure during dialysis treatment. 
Citation: Shintani H, Hayashi F (2011) Analytical Validation of Ameziniummetilsulfate by HPLC in Human Blood Plasma from Uremia Patient Treated by Dialysis. Pharm Anal Acta S11:004. doi:10.4172/2153-2435.S11-004

Page 4 of 6

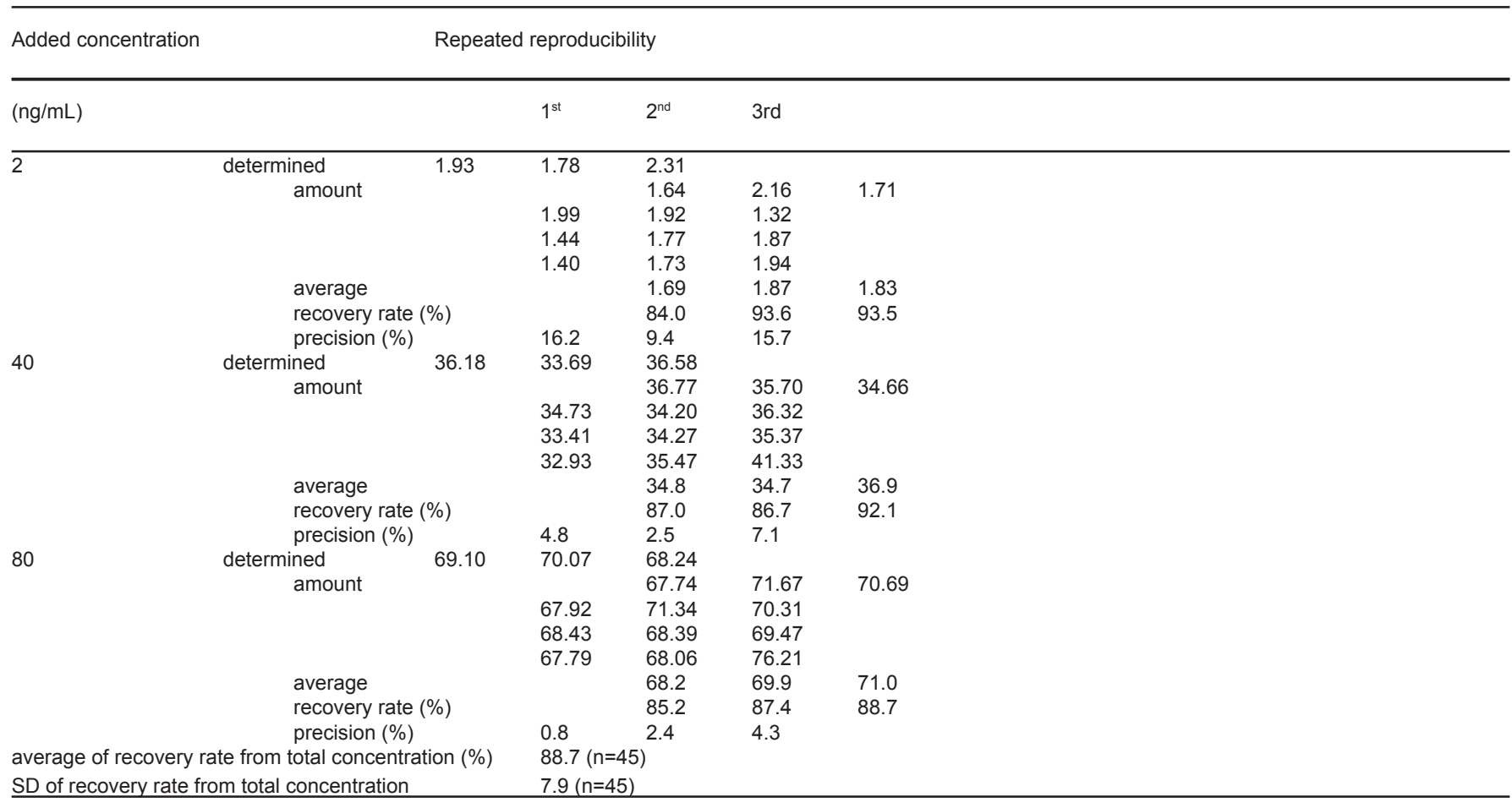

SD: standard deviation

Table 2: Recovery rate of ameziniummetilsulfate (AM) when confirming reproducibility

\begin{tabular}{|c|c|c|c|c|c|c|c|}
\hline \multicolumn{2}{|l|}{$\begin{array}{l}\text { Added concentration } \\
(\mathrm{ng} / \mathrm{mL})\end{array}$} & \multicolumn{3}{|c|}{ Repeated reproducibility } & \multicolumn{2}{|c|}{$\begin{array}{l}\text { Intra-laboratory } \\
\text { reproducibility }\end{array}$} & \\
\hline \multirow[t]{8}{*}{2} & determined & 2.18 & 2.01 & 2.60 & & & \\
\hline & amount & & & 1.85 & 2.44 & 1.93 & 1.89 \\
\hline & & & 2.24 & 2.16 & 1.71 & 2.11 & \\
\hline & & & 1.62 & 2.00 & $2.11 q$ & 2.11 & \\
\hline & & & 1.58 & 1.95 & 2.19 & & \\
\hline & average & & & 1.9 & 2.1 & 2.1 & 2.0 \\
\hline & accuracy (\%) & & -5.3 & +5.6 & +5.4 & +1.8 & \\
\hline & precision (\%) & & 16.2 & 9.4 & 15.7 & 6.2 & \\
\hline \multirow[t]{8}{*}{40} & determined & 40.79 & 37.98 & 41.24 & & & \\
\hline & amount & & & 41.45 & 40.25 & 39.08 & 39.24 \\
\hline & & & 39.15 & 38.56 & 40.95 & 39.08 & \\
\hline & & & 37.67 & 38.64 & 39.88 & 41.55 & \\
\hline & & & 37.13 & 39.99 & 46.60 & & \\
\hline & average & & & 39.2 & 39.1 & 41.6 & 40.0 \\
\hline & accuracy (\%) & & -1.9 & -2.3 & +3.9 & -0.1 & \\
\hline & precision (\%) & & 4.8 & 2.5 & 7.1 & 3.5 & \\
\hline \multirow[t]{8}{*}{80} & determined & 77.90 & 79.00 & 76.93 & & & \\
\hline & amount & & & 76.37 & 80.80 & 79.70 & 76.88 \\
\hline & & & 76.57 & 80.43 & 79.27 & 78.81 & \\
\hline & & & 77.15 & 77.10 & 78.32 & 80.03 & \\
\hline & & & 76.43 & 76.73 & 85.92 & & \\
\hline & average & & & 76.9 & 78.8 & 80.0 & 78.6 \\
\hline & accuracy (\%) & & -3.9 & -1.5 & +0.04 & -1.8 & \\
\hline & precision (\%) & & 0.8 & 2.4 & 4.3 & & \\
\hline
\end{tabular}

Table 3: Reproducibility of ameziniummetilsulfate (AM) determination.

Depending on individual patients, the AM time course differed. This is thought to be due to: difference of sensitivity of AM, difference of metabolism activity and concentration of enzymes in individuals.

The individual time course data from three patients administered $\mathrm{AM}$ and treated by artificial dialysis is in Figure 3.

According to Figure 3, the concentration of blood AM increased, but $4 \mathrm{~h}$ is the maximum time for dialysis treatment per dialysis in general. The concentration of AM in blood is not a maximum after that time (Figure 3). This indicates earlier administration prior to artificial dialysis is thought to be more desirable.

\section{Conclusion}

In order to establish the HPLC determination of AM in human plasma, an ionsuppression, reverse-phase C-18 HPLC method is described. No interfering peaks could be observed regarding specificity 
Citation: Shintani H, Hayashi F (2011) Analytical Validation of Ameziniummetilsulfate by HPLC in Human Blood Plasma from Uremia Patient Treated by Dialysis. Pharm Anal Acta S11:004. doi:10.4172/2153-2435.S11-004

Page 5 of 6

\begin{tabular}{lllll}
\hline Prepared concentration & \multicolumn{2}{l}{ Period after preparation (week, $\left.-80^{\circ} \mathrm{C}\right)$} & freeze-resolution \\
$(\mathrm{ng} / \mathrm{mL})$ & 0 & 1 & 2 & 2 times \\
\hline 2 & 2.0 & 2.2 & 2.3 & 2.2 \\
40 & 40.0 & 41.4 & 41.0 & 40.0 \\
\hline Data is the average of 3 samples & & &
\end{tabular}

Data is the average of 3 samples

Table 4: Stability of ameziniummetilsulfate (AM) in human blood plasma.

\begin{tabular}{llllllll}
\hline $\begin{array}{l}\text { Concentration } \\
\text { (ng/mL) }\end{array}$ & 0.04 & 0.1 & 0.2 & 0.4 & 0.8 & 1.6 \\
\hline $\begin{array}{l}\text { peak area } \\
\text { (u V.S) }\end{array}$ & $\begin{array}{l}\text { standard solution } \\
\text { tested } \\
\text { control solution }\end{array}$ & 5178 & 13941 & 26410 & 54303 & 107938 & 214381 \\
\hline
\end{tabular}

Table 5: Stability of ameziniummetilsulfate (AM) standard solution.

\begin{tabular}{lllll}
\hline Prepared concentration & \multicolumn{3}{l}{ Period after preparation (day) } \\
(ng/mL) & 0 & 1 & 2 & 3 \\
\hline 2 & 2.3 & 2.0 & 2.6 & 2.1 \\
40 & 38.5 & 42.1 & 38.9 & 40.0 \\
\hline Data is the average of 3 samples & & &
\end{tabular}

Table 6: Stability of ameziniummetilsulfate (AM) in autosampler.

\begin{tabular}{llll}
\hline Prepared concentration & \multicolumn{3}{l}{ Evaporation period (min) } \\
(ng/mL) & 15 & 30 & 60 \\
\hline 2 & 1.8 & 1.7 & 2.2 \\
40 & 41.1 & 41.7 & 42.5 \\
\hline
\end{tabular}

Data is the average of 3 samples

Table 7: Stability of ameziniummetilsulfate (AM) in evaporation condition.

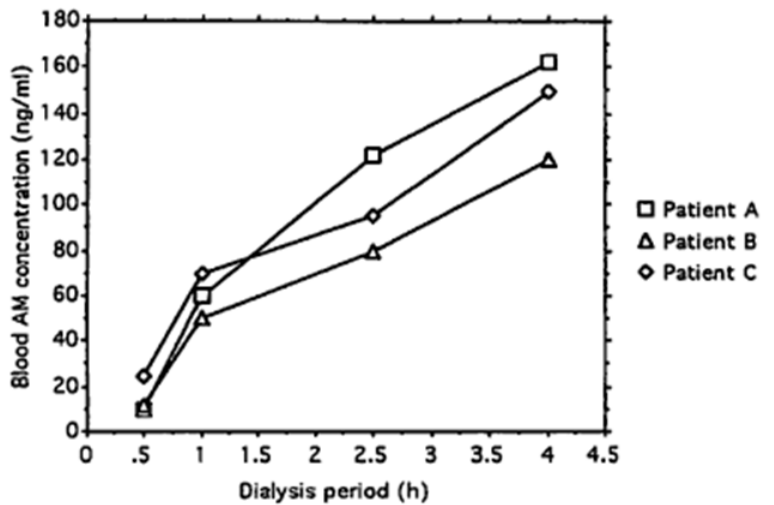

Figure 3: Time course of AM in human plasma of uremia patient treated by artificial dialysis for pharmacokinetic study.

and selectivity of established HPLC and pretreatment methods.

Concerning reproducibility, accuracy was -5.3 to $+5.6 \%$ and precision $0.8-16.2 \%$, which was satisfactory. The limit of determination (LOD) was $2 \mathrm{ng} / \mathrm{mL}$. This concentration was sufficient to determine AM in uremia patients. Stability test indicated AM in human plasma would maintain satisfactory quality for 2 consecutive weeks at $-80^{\circ} \mathrm{C}$.

From the established analytical validation results, satisfactory specificity and reproducibility were attained. $2.0 \mathrm{ng} / \mathrm{mL}$ LOD was good enough for determination of AM in human plasma. This method is applicable to blood AM of uremia patients treated by artificial dialysis. This is important because during dialysis, AM will be eluted from blood due to Donnan membrane equilibria, thus blood AM may decrease not only metabolism, but is also eluted from artificial dialysis membranes. However, blood AM treated by artificial dialysis can be adequately determined by the analytical method established above.

\section{References}

1. Hayashi F, Namiki S, Namiki T(2000) J Dialysis 33: 279-285.

2. Shintani H, Hayashi F (2003) J Antibact Antifung Ass. 31: 77-84.

3. Kaumeier S, Kehrhahn OH, Morgenthaler H, Neugebauer G (1981) Absolute bioavailability of amezinium. A cross-over study after i.v. and p.o. application. Arzneimittelforschung 31:1653-1657.

4. Wilsmann K, Neugebauer G, Kessel R, Lang E (1981) Cardiovascular effects of amezinium in humans during passive upright tilt in comparison with norfenefrine and dihydroergotamine. Arzneimittelforschung 31: 1647-1652.

5. Wilsmann K, Neugebauer G, Kessel R, Lang E (1981) Haemodynamic effects of amezinium in man Arzneimittelforschung 31: 1638-1646.

6. Moest T, Dechow HJ, Pich CH (1981) The galenic development of a tablet with ameziniummetilsulfate. Arzneimittelforschung 31: 1623-1638.

7. Traut $M$, Kummer H, Brode $E$ (1981) The fate of amezinium in humans and animals. Arzneimittelforschung 31:1616-1622.

8. Traut M, Brode E (1981) Pharmacokinetics of amezinium in man Arzneimittelforschung 31: 1605-1615.

9. Traut M, Brode E, Neumann B, Kummer H (1981) Pharmacokinetics of amezinium in rat and dog. Arzneimittelforschung 31: 1594-1604.

10. Teschendorf HJ, Kretzschmar R, Kreiskott H, Weifenbach H (1981) Arzneimittelforschung 1981,31,1580-1588.

11. Muller CD, Gries J, Lenke D, Teschendorf HJ, Weifenbach H (1981) Pharmacology of amezinium, a novel antihypotensive drug. V. Effect on visceral, renal, metabolic and sensory functions. Arzneimittelforschung 31 : 1574-1579.

12. Traut M, Brode E, Hoffmann HD (1981) Pharmacology of amezinium, a nove antihypotensive drug. IV. Biochemical investigations of the mechanism of action .Arzneimittelforschung 31: 1566-1574.

13. Lenke D, Gries J, Kretzschmar R (1981) Pharmacology of amezinium a novel antihypotensive drug. III. Studies on the mechanism of action. Arzneimittelforsclmng 3: 1558-1565.

14. Lehmann HD, Giertz H, Kretzschmar R, Lenke D, von Philipsborn G, et 
Citation: Shintani H, Hayashi F (2011) Analytical Validation of Ameziniummetilsulfate by HPLC in Human Blood Plasma from Uremia Patient Treated by Dialysis. Pharm Anal Acta S11:004. doi:10.4172/2153-2435.S11-004

Page 6 of 6

al. (1981) Pharmacology of amezinium, a novel antihypotensive drug. II. Examination of cardiovascular effects. Arzneimittelforschung 31: 1544-1557.

15. Gries J, Schuster J, Giertz H, Lehmann HD, Lenke D, et al. (1981) Pharmacology of amezinium, a novel antihypotensive drug. I. Comparative studies of the effect on blood pressure and heart rate. Arzneimittelforschung 31:15331543.

16. Reicheneder F, Burger TF, Konig H, Kropp R, Lietz H, et al. (1981) Amezinium. Synthesis and radioactive labelling. Arzneimittelforschung 31: 1529-1533.

17. Oloff SH (1981) A synopsis of the therapeutic trials of amezinium. Arzneimittelforschung 31: 1657-1671.

18. Traut M, Morgenthaler H, Brode E (1981) Determination of amezinium in body fluids. Arzneimittelforschung 31: 1589-1593.

19. Hotz D, Brode E J (1983) High-performance liquid chromatographic determination of amezinium in human plasma. Clrromatogr 14: 217-227.

20. Shintani HJ (1994) Selection of Columns for Analysis of Blood Urea. Journal of Liquid Chromalgr 17: 1737-1742.

21. Shintani HJ (1995) Solid Phase Extraction (SPE) of Blood Urea Compared with Liquid-Liquid Extraction Regarding Artifact Formation. Jolurnal of Liquid Chromatgr 18: 2167-2174.

22. Shintani H (1995) J Liquid Clrromalgr 18: 613-626.
This article was originally published in a special issue, Pharamacokinetics Validation, Metabolism, etc. handled by Editor(s). Dr. Hideharu Shintani,

Chuo University, Japan 